\title{
A latent class analysis of dietary behaviours associated with metabolic syndrome: a retrospective observational cross-sectional study
}

\author{
Jung Ha Park ${ }^{1}$, Ju Young Kim ${ }^{2^{*}}$ D, So Hye Kim³ ${ }^{3}$ Jung Hyun $\mathrm{Kim}^{4}$, Young Mi Park ${ }^{3}$ and Hye Seon Yeom ${ }^{3}$
}

\begin{abstract}
Background: Obesity defined solely by the Body Mass Index (BMI) may not reflect the true heterogeneity of the obese population. This study aimed to classify the dietary behaviours of overweight and obese individuals and to explore the relationship between patterns of dietary behaviour and cardiometabolic risk factors.

Methods: A total of 259 patients who visited an outpatient weight management clinic at a tertiary hospital and underwent a dietary behaviour assessment between January 2014 and February 2019 were enrolled in the study. Dietary behaviours were assessed in three domains with nine categories, including choice of food (frequently eating out and consumption of instant/fast/takeaway food), eating behaviour (irregular meals; frequent snacking, including eating at night; emotional eating; and overeating/binge eating), and nutrient intake (high-fat/high-calorie foods, salty food, and poorly balanced diet). Latent class analysis (LCA) was used to classify the subjects according to these categories. Associations between latent class and metabolic syndrome were assessed by logistic regression.

Results: The subjects were classified into three LCA-driven classes, including a referent class of healthy but unbalanced eaters $(n=118)$, a class of emotional eaters $(n=53)$, and a class of irregular unhealthy eaters $(n=88)$. Compared with the referent class, emotional eaters had a significantly higher BMI (beta $=3.40, P<0.001$ ) accompanied by metabolic syndrome (odds ratio 2.88, 95\% confidence interval 1.16-7.13).

Conclusions: Our three LCA-driven obesity phenotypes could be useful for assessment and management of obesity and metabolic syndrome. The association between emotional eaters and higher BMI and metabolic syndrome was stronger than that with other eaters. Thus, emotional regulation strategies might have benefit for emotional eater's diet.
\end{abstract}

Keywords: Dietary behaviour, Eating behaviour, Emotional eating, Mealtimes, Meal frequency, Obesity, Metabolic syndrome, Latent class analysis

\footnotetext{
* Correspondence: kkamduri@snubh.org; kkamburi@gmail.com ${ }^{2}$ Department of Family Medicine, Seoul National University Bundang Hospital and Seoul National University College of Medicine, 82, Gumi-ro 173 Beon-gil, Bundang-gu, Seongnam, Gyeonggi-do 13620, Republic of Korea Full list of author information is available at the end of the article
}

(c) The Author(s). 2020 Open Access This article is licensed under a Creative Commons Attribution 4.0 International License, which permits use, sharing, adaptation, distribution and reproduction in any medium or format, as long as you give appropriate credit to the original author(s) and the source, provide a link to the Creative Commons licence, and indicate if changes were made. The images or other third party material in this article are included in the article's Creative Commons licence, unless indicated otherwise in a credit line to the material. If material is not included in the article's Creative Commons licence and your intended use is not permitted by statutory regulation or exceeds the permitted use, you will need to obtain permission directly from the copyright holder. To view a copy of this licence, visit http://creativecommons.org/licenses/by/4.0/. The Creative Commons Public Domain Dedication waiver (http://creativecommons.org/publicdomain/zero/1.0/) applies to the data made available in this article, unless otherwise stated in a credit line to the data. 


\section{Background}

The World Health Organization has declared obesity to be a global epidemic with a prevalence that has tripled since 1975 and complications that have led to the death of at least 2.8 million individuals worldwide [1]. Moreover, 35\% of Korean adults aged $\geq 18$ years are reported to be obese [2].

Obesity is defined as abnormal or excess accumulation of fat that endangers health [1]. Although the Body Mass Index (BMI) is widely used to classify overweight and obesity, there are some caveats when using this value to determine excess body fat, the main one being that BMI does not discriminate between lean body mass and fat mass. Therefore, BMI can overestimate body fat in muscular athletes and underestimate sarcopenia in older adults [3]. Moreover, the cardiometabolic risks of obesity and their heterogeneity cannot be assessed by BMI alone [4].

Obesity is a consequence of multiple genetic, socioeconomic, lifestyle, and environmental factors. However, the main driver of the obesity pandemic is likely to be changes in the global food system and accompanying changes in dietary behaviour [5, 6]. Several studies have shown a close link between obesity and dietary behaviour. Particularly snacking in the absence of hunger [7], consumption of fast foods [8], binge eating or food addiction [9], vulnerability to external food cues [10], preference for foods high in calories, fat, sugar, and salt, and frequently eating outside the home [11].

It is important to recognise the complex factors that shape and influence dietary behaviour, which can be classified as food choice, eating behaviour, and dietary/nutritional intake [12]. Food choice includes behaviours and other factors that precede food intake, such as preferences, frequency of purchase, food preparation, and intentions. Eating behaviour is categorised as eating habits, eating occasions, portion size, dieting, symptoms of disordered eating, and 'pickiness'. Dietary/nutritional intake includes the specifics of what is consumed, such as dietary pattern, meal pattern, food intake, and food components.

Awareness of the different types of dietary behaviour has prompted a recommendation for a tailored approach to the treatment of obesity [13]. Conceptualising and classifying subtypes of obese individuals according to their dietary behaviour might allow more personalised and effective behavioural and nutritional treatments.

Latent class analysis (LCA) has been widely used to classify dietary behaviours associated with obesity [14-16]. It can also be used to divide a population into mutually exclusive subgroups and classify them exhaustively based on the intersection of multiple observed characteristics [17].

\section{Methods}

Aims, study design, and participants

The aims of this study were to classify the dietary behaviour of overweight or obese individuals into subgroups using LCA and to explore the relationship between each of these subgroups and cardiometabolic risk factors. This cross-sectional study was based on a retrospective review of the medical records of 259 patients who visited an outpatient weight management clinic at a tertiary hospital and underwent a dietary behaviour assessment between January 2014 and February 2019. Patients who were younger than 18 years, those for whom height or weight data were missing, and those with no dietary behaviour assessment records were excluded. The study protocol was approved in advance of enrolling patients by the Institutional Review Board at Seoul National University Bundang Hospital (IRB no. B-1904-532-114). The need for informed consent was waived in view of the retrospective nature of the study and the anonymity of the data.

\section{Sociodemographic and clinical variables}

Our outpatient weight management clinic is attended by obese patients who want to lose weight or are referred by other departments. Patients who attend this clinic initially complete a self-administered questionnaire designed to collect information on sociodemographic and lifestyle factors, a weight history, and eating-related behaviours, and then attend a consultation with a family physician specialised in obesity management. At the next session, a dietician performs a dietary assessment, provides the patient with detailed education on nutrition, and prescribes a low or very low calorie diet. Next, the patient attends an appointment with a doctor who checks for adherence or barriers to the prescribed diet or the exercise recommendations and, if needed, prescribes appetite-suppressing medication. These sessions are repeated at intervals of 2 weeks for 1 month, 4 weeks for 2 months, and 8 weeks for 4 months until the patient has achieved a weight decrease of at least $10 \%$ of the initial body weight. Patients are then encouraged to attend a weight loss maintenance program, where they learn strategies for maintaining the weight lost, and regular follow-up sessions for at least 12 months.

In this study, we collected sociodemographic information on sex, age, income, and level of education from the self-completed questionnaires. Lifestyle factors, such as smoking, hazardous drinking, and frequency of exercise, were included. Anthropometric measurements, including height, weight, systolic and diastolic blood pressure, and body fat were obtained by bioelectrical impedance analysis using the InBody 720 device (BioSpace Inc., Urbandale, IA, USA). Clinical variables included total cholesterol, high-density and low-density lipoprotein cholesterol (HDL and LDL cholesterol), triglycerides (TG), fasting blood glucose (FBS), glycated haemoglobin $\left(\mathrm{HbA}_{1 \mathrm{C}}\right)$, estimated glomerular filtration rate and liver function tests including aspartate transaminase (AST), 
alanine transaminase (ALT) and gamma-glutamyl transferase (GGT).

Since mood disorders such as depression might affect eating behaviours of study subjects, we extracted the patient's diagnosis of depression by using the tenth revision of the International Statistical Classification of Diseases and Related Health Problems (ICD-10). An ICD-10 diagnosis of F20.4, F31.3-F31.5, F32.x, F33.x, F34.1, F41.2, or F43.2 and two depression prescriptions given within a 1-year period were considered proxies for having depression [18]. Diagnosis was extracted using electronic medical records for a period of approximately 2 years from the day the questionnaire was conducted.

Using the National Cholesterol Education ProgramAdult Treatment Panel III criteria for Asian populations [19], a diagnosis of metabolic syndrome was made when at least three of the following five conditions were met:

- High blood pressure (systolic $\geq 130 \mathrm{mmHg}$ or diastolic $\geq 85 \mathrm{mmHg}$ ) or on antihypertensive medication

- High FBS level ( $\geq 100 \mathrm{mg} / \mathrm{dL}$ ) or current use of oral antidiabetic medication

- High TG level ( $\geq 150 \mathrm{mg} / \mathrm{dL}$ ) or current use of lipidlowering medication

- HDL cholesterol (<40 mg/dL in men, $<50 \mathrm{mg} / \mathrm{dL}$ in women)

- Abdominal obesity $(\geq 90 \mathrm{~cm}$ in $\mathrm{men}, \geq 85 \mathrm{~cm}$ in women)

\section{Dietary behaviour assessment}

The self-administered dietary behaviour questionnaire included the following items, each of which was rated on a 5-point Likert scale: frequency of meals, skipping meals, frequent snacking or night eating, overeating or binge eating, preference for fatty foods or carbohydrates, consumption of instant food such as ramen, fast foods such as pizza or hamburgers, greasy food such as fried chicken, intake of sugar-sweetened beverages, and frequency of intake of carbohydrates, vegetables and fruit, protein, fat and dairy products; Table 1). Based on previous studies [20-23], we organised our dietary behaviour questions into three main domains with the following nine categories: food choice (frequently eating out, consumption of fast food, instant food, and takeaway food), eating behaviour (irregular meals, frequent snacking including at night, emotional eating, and overeating/binge eating), and nutritional intake (high-fat/high-calorie foods, salty food, and poorly balanced food intake).

We reclassified the food choice and eating behaviour domains as dichotomous variables and recorded 'yes' if items in those categories were responded to as 'frequently' or 'very frequently'. For nutritional balance, we referenced the nutrition quotient calculation for Korean adults [24]. Briefly, the Korean nutrition quotient consists of nutrition balance, food diversity, moderation of amount of food intake, and dietary behaviour. Nutritional balance assesses the intake of vegetable/fruit, protein (fish, eggs, and beans), nuts and milk, and dairy products. If the calculated nutrition balance score was in the lower quartile, food intake was classified as unbalanced.

High-fat/high-calorie intake included high consumption of fatty foods, such as fried food, meat, ham, or sausage, and high consumption of sugar-sweetened beverages or foods containing sugar. Each score was summed to yield a mean score. If the mean high-fat/ high-calorie score was $>4$, it was classified as 'yes', as for a dichotomous variable. Other latent variables were classified as 'yes' or 'no' according to the corresponding mean scores.

\section{Statistical methods}

Continuous variables are presented as mean and standard deviation and categorical variables as the frequency count and percentage. LCA was performed using PROC LCA (version 1.3.2) [25-27] and was used to classify the patients into nine subtypes of dietary behaviour. The Akaike information criterion and Bayesian information criterion were used to find the best representative number of subgroups in these data. The number of classes was selected by a combination of parsimony and interpretability, and the class number can be possibly used as a meaningful label for each class [27]. Each class was described in terms of sociodemographic factors, anthropometric measurements, and laboratory results.

We examined the association between LCA-derived classes and cardiometabolic risk factors using the LCA distal outcome Macro program (http://methodology.psu. edu/downloads). Briefly, LCA with a distal outcome was constituted with a 'three-step' method (Bolck-CroonHagenaars method) [28], whereby the parameters of the LCA model are first estimated without the distal outcome, the posterior probabilities of class membership are then used to compute a weighting variable, and finally, the weighting variable is used to calculate a weighted average of outcomes for each class. The LCA-driven classes were subsequently entered into a logistic regression model to test for associations between each class (with the relatively healthy class chosen as the referent) and the risk of metabolic syndrome with adjustment for age, sex, healthy behaviours, BMI, and other clinical variables. All statistical analyses were performed using SAS version 9.3 (SAS Institute Inc., Cary, NC, USA).

\section{Results}

LCA identified three classes of study subjects. The model fit indices are summarised in Table 2. LCA 
Table 1 Dietary behaviour questionnaires

\begin{tabular}{|c|c|c|}
\hline Category & Dietary behaviour & Question \\
\hline \multirow[t]{4}{*}{ Food choice } & \multirow[t]{2}{*}{ Frequently eating out } & Do you usually eat out (except staff restaurant) about twice a week? \\
\hline & & Do you overeat when you eat out (except in the staff cafeteria)? \\
\hline & \multirow{2}{*}{$\begin{array}{l}\text { Fast/instant/takeaway } \\
\text { food }\end{array}$} & Do you eat bread, pizza, and chicken instead of your regular meal at dinner? \\
\hline & & Do you often eat instant food or fast food such as ramen? \\
\hline \multirow{15}{*}{$\begin{array}{l}\text { Eating } \\
\text { behaviour }\end{array}$} & \multirow{3}{*}{$\begin{array}{l}\text { Meal irregularity and } \\
\text { speed }\end{array}$} & How often do you skip meal? \\
\hline & & Do you eat at a regular time? \\
\hline & & How fast do you eat your meal? \\
\hline & \multirow{3}{*}{$\begin{array}{l}\text { Frequent or night } \\
\text { snacking }\end{array}$} & Do you eat snacks within $3 \mathrm{~h}$ before sleep? \\
\hline & & Do you eat your dinner late at night? \\
\hline & & Do you sometimes eat snacks when you are watching TV or reading the newspaper? \\
\hline & \multirow[t]{5}{*}{ Overeating/binge eating } & Do you eat more food than you had planned to? \\
\hline & & Can you stop eating when you are full? \\
\hline & & Do you continue to eat even after you feel like stopping? \\
\hline & & Do you overeat frequently? \\
\hline & & Do you sometimes eat food although you are not hungry? \\
\hline & \multirow[t]{4}{*}{ Emotional eating } & Do you eat food on impulse? \\
\hline & & Do you eat food when you feel depressed or unhappy? \\
\hline & & Do you eat food when you feel anxiety or stress? \\
\hline & & Do you feel that you can recover yourself through eating sugary food? \\
\hline \multirow[t]{11}{*}{ Nutrient } & \multirow[t]{4}{*}{ High-calorie dense food } & Do you eat foods containing sugar (crackers, candy, chocolates, cakes, ice cream) every day? \\
\hline & & Do you drink soft drinks, vitamin drinks, or fruit juice instead of water \\
\hline & & Do you often eat greasy food such as fried food, stir-fries, or salad dressing? \\
\hline & & Do you like meat? \\
\hline & \multirow[t]{3}{*}{ Salty food } & Do you usually eat a lot of kimchi or salt-pickled vegetables? \\
\hline & & Do you eat all the broth in soups or stews? \\
\hline & & Do you often add salt or soy sauce before eating soups? \\
\hline & \multirow[t]{4}{*}{ Unbalanced food } & Are you having fruits or fruit juice every day? \\
\hline & & Do you eat vegetables in each meal (except kimchi)? \\
\hline & & $\begin{array}{l}\text { Are you eating at least one of the following foods: meat, fish, egg, bean, and tofu when you have a } \\
\text { meal? }\end{array}$ \\
\hline & & Do you prefer to eat multi-grain rice over white rice? \\
\hline
\end{tabular}

Table 2 Model-fit indices for the latent class analysis model

\begin{tabular}{llllll}
\hline Number of classes & AIC & BIC & Likelihood ratio G & Degrees of freedom & Entropy \\
\hline 2 & 341.7 & 409.3 & 303.7 & 492 & 0.70 \\
3 & 322.5 & 425.6 & 264.5 & 482 & 0.73 \\
4 & 313.3 & 452.0 & 235.3 & 472 & 0.72 \\
5 & 315.8 & 490.1 & 217.8 & 462 & 0.75 \\
6 & 318.7 & 528.5 & 200.7 & 452 & 0.78 \\
7 & 325.8 & 571.3 & 187.8 & 442 & 0.82 \\
8 & 334.8 & 615.8 & 176.8 & 432 & 0.80 \\
9 & 343.7 & 660.3 & 165.7 & 422 & 0.83 \\
\hline
\end{tabular}


models with 2-9 classes were compared for model fit and interpretability. We chose a three-class model that showed the best fit measured by a lower Bayesian information criterion with higher entropy.

Figure 1 shows the conditional probabilities for each dietary behaviour in each class. Class 1 subjects (healthy but unbalanced eaters, $n=118$ ) generally had regular meals and fewer snacks, reported less emotional eating, and did not eat fast/instant/takeaway food but tended to have a poorly balanced food intake. Class 2 subjects (irregular, unhealthy eaters, $n=88$ ) were characterised by frequently eating out, irregular meal intake, a preference for calorie-dense food, and poorly balanced food intake, but no emotional eating. Class 3 (emotional eaters, $n=$ 53) had a very high probability of emotional eating, binge eating, preference for calorie-dense food, irregular meals, and frequent eating at night.

Table 3 summarises the sociodemographic and clinical factors and the health-related behaviours in each class. Subjects in the emotional eating group were younger, had a higher BMI, and were more likely to be female than those in the other two groups. Furthermore, the prevalence of metabolic syndrome was $49 \%$ in the emotional eating group and 32\% in both the healthy eating and irregular unhealthy eating groups. The emotional eaters were more likely to exercise regularly and less likely to smoke or consume alcohol than the other two groups.

Table 4 shows the association between latent class and cardiometabolic risk factors. There were significant differences in BMI, waist circumference, and body fat percentage between the three classes. BMI, waist circumference, and body fat percentage values were lower in class 1 (the healthy referent group) than in classes 2 and 3, with no differences between classes 2 and class 3 . No significant differences were found in the cardiometabolic variables between the three classes, except for GGT, which was higher in class 2 than in class 1 . The prevalence of metabolic syndrome was higher in class 3 than in class 1.

Logistic regression was performed to evaluate the associations between the three LCA-driven classes and metabolic syndrome using healthy but unbalanced eaters as the referent group (Table 5). Significant association of metabolic syndrome with emotional eating, but not with irregular unhealthy eating (class 2), was found when compared with the referent group (class 1). Logistic regression analysis showed that metabolic syndrome was associated with a higher BMI, an increase in liver enzyme levels ( $>120 \mathrm{mg} / \mathrm{dL}$, equivalent to three times the upper limit of normal), and current smoking.

\section{Discussion}

In this study, subtyping of dietary behaviour in overweight or obese individuals identified three latent classes (healthy but unbalanced eaters, irregular unhealthy eaters, and emotional eaters). Moreover, we identified a significant association between emotional eating and a higher BMI, waist circumference, and body fat percentage. Importantly, emotional eaters also had a higher

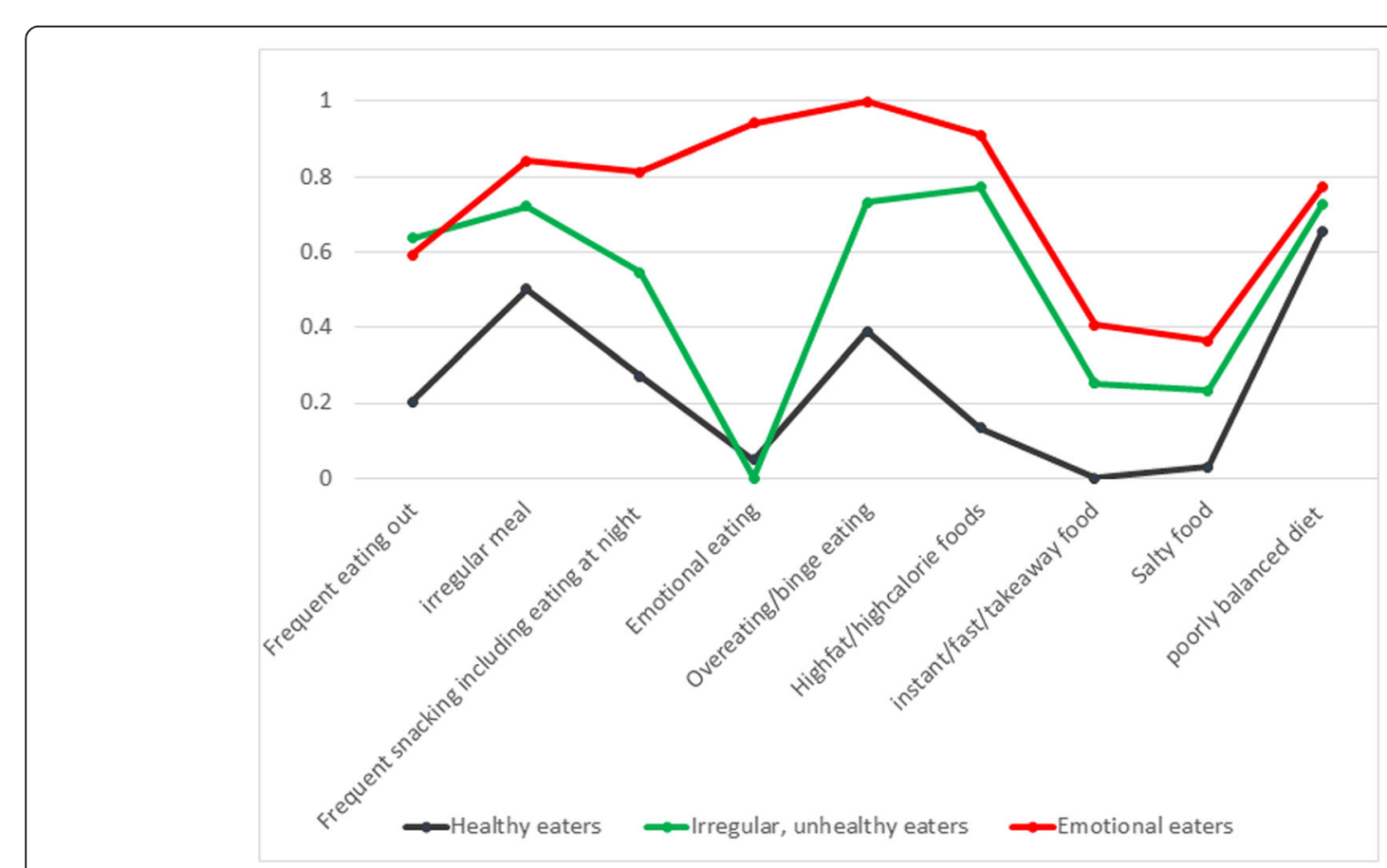

Fig. 1 Item probabilities in the three latent classe 
Table 3 Baseline characteristics according to LCA-derived classes

\begin{tabular}{|c|c|c|c|}
\hline & $\begin{array}{l}\text { Class } 1 \\
\text { Healthy but unbalanced eaters }\end{array}$ & $\begin{array}{l}\text { Class } 2 \\
\text { Irregular, unhealthy eaters }\end{array}$ & $\begin{array}{l}\text { Class } 3 \\
\text { Emotional eaters }\end{array}$ \\
\hline$n$ & 118 & 88 & 53 \\
\hline Age, years & $50.8(10.0)$ & $46.5(9.8)$ & $42.6(9.7)$ \\
\hline \multicolumn{4}{|l|}{ Sex } \\
\hline Male & $76(64)$ & $65(74)$ & $22(42)$ \\
\hline Female & $42(36)$ & $23(26)$ & $31(58)$ \\
\hline \multicolumn{4}{|l|}{ Underlying disease } \\
\hline Hypertension & $38(42)$ & $33(65)$ & $10(28)$ \\
\hline Diabetes & $16(20)$ & $9(18)$ & $4(18)$ \\
\hline Hyperlipidaemia & $28(33)$ & $29(45)$ & $15(47)$ \\
\hline Depression & $13(11)$ & $13(15)$ & $7(13)$ \\
\hline Body Mass Index, kg/m² & $27.2(3.5)$ & $28.0(3.5)$ & $30.7(4.1)$ \\
\hline Body fat percentage & $29.5(6.6)$ & $28.9(6.5)$ & $34.8(7.2)$ \\
\hline Waist circumference, $\mathrm{cm}$ & $93.8(8.5)$ & $95.2(8.4)$ & $99.5(10.0)$ \\
\hline Systolic blood pressure, $\mathrm{mmHg}$ & $119.3(14.2)$ & $120.8(15.4)$ & $124.1(14.9)$ \\
\hline Diastolic blood pressure, $\mathrm{mmHg}$ & $71.6(10.0)$ & $72.5(11.5)$ & $72.9(8.9)$ \\
\hline \multicolumn{4}{|l|}{ Education, n (\%) } \\
\hline High school & $52(44)$ & $33(38)$ & $18(34)$ \\
\hline More than college & $66(56)$ & $55(63)$ & $35(66)$ \\
\hline \multicolumn{4}{|l|}{ Income per month, n (\%) } \\
\hline Less than 8000 USD & $42(38)$ & $20(25)$ & $8(17)$ \\
\hline More than 8000 USD & $70(63)$ & $60(75)$ & $39(83)$ \\
\hline \multicolumn{4}{|l|}{ Smoking, n (\%) } \\
\hline No & $46(43)$ & $29(37)$ & $28(65)$ \\
\hline Ex & $35(33)$ & $24(31)$ & $7(16)$ \\
\hline Yes & $26(24)$ & $25(32)$ & $8(19)$ \\
\hline \multicolumn{4}{|l|}{ Drinking, n (\%) } \\
\hline No & $37(32)$ & $27(31)$ & $23(45)$ \\
\hline Yes & $77(68)$ & $59(69)$ & $28(55)$ \\
\hline \multicolumn{4}{|l|}{ Exercise, n (\%) } \\
\hline Regular & $75(69)$ & $60(71)$ & $45(87)$ \\
\hline None & $34(31)$ & $24(29)$ & $7(13)$ \\
\hline \multicolumn{4}{|l|}{ Clinical laboratory findings } \\
\hline $\mathrm{FBS}, \mathrm{mg} / \mathrm{dL}$ & $102.4(26.8)$ & $102.0(22.7)$ & $100.4(35.0)$ \\
\hline $\mathrm{HbA} 1 \mathrm{c}, \%$ & $5.9(0.9)$ & $5.9(0.9)$ & $5.9(1.1)$ \\
\hline Total cholesterol, mg/dL & $201.3(38.9)$ & $194.2(35.0)$ & $198.6(45.0)$ \\
\hline $\mathrm{TG}, \mathrm{mg} / \mathrm{dL}$ & $153.0(100.4)$ & $158.2(96.0)$ & $152.1(111.6)$ \\
\hline HDL cholesterol, mg/dL & $50.8(13.2)$ & $49.3(10.4)$ & $49.2(11.3)$ \\
\hline LDL cholesterol, mg/dL & $124.3(32.1)$ & $118.4(30.3)$ & $122.3(36.0)$ \\
\hline $\mathrm{eGFR}, \mathrm{mL} / \mathrm{min}$ & $94.7(17.5)$ & $97.9(18.9)$ & $105.3(19.5)$ \\
\hline $\mathrm{AST}, \mathrm{mg} / \mathrm{dL}$ & $33.2(26.8)$ & $35.1(38.8)$ & $29.4(14.1)$ \\
\hline $\mathrm{ALT}, \mathrm{mg} / \mathrm{dL}$ & $40.9(35.8)$ & $48.8(52.4)$ & $41.7(27.9)$ \\
\hline $\mathrm{GGT}, \mathrm{mg} / \mathrm{dL}$ & $47.4(42.5)$ & $59.0(50.2)$ & $41.1(25.4)$ \\
\hline Metabolic syndrome, n (\%) & $37(32)$ & $25(32)$ & $21(49)$ \\
\hline
\end{tabular}

AST aspartate transaminase, ALT alanine transaminase, eGFR estimated glomerular filtration rate, FBS fasting blood glucose, GGT gamma glutamyl transferase, $H b A_{1 C}$ glycated haemoglobin, $H D L$ high-density lipoprotein, $L D L$ low-density lipoprotein, $T G$ triglycerides 
Table 4 Association between latent classes and cardiometabolic risk factors

\begin{tabular}{|c|c|c|c|c|}
\hline Difference in means & Estimate & SE & Wald statistic & $P$-value \\
\hline \multicolumn{5}{|l|}{ Body mass index } \\
\hline Class 1 vs. class 2 & 2.70 & 0.77 & 12.3 & $<0.001$ \\
\hline Class 1 vs. class 3 & 3.40 & 069 & 23.9 & $<0.001$ \\
\hline Class 2 vs. class 3 & 0.71 & 0.67 & 1.12 & 0.290 \\
\hline Omnibus test & & & 24.56 & $<0.001$ \\
\hline \multicolumn{5}{|l|}{ Waist circumference } \\
\hline Class 1 vs. class 2 & 4.09 & 1.94 & 4.42 & 0.035 \\
\hline Class 1 vs. class 3 & 5.34 & 1.76 & 9.15 & $<0.01$ \\
\hline Class 2 vs. class 3 & 1.26 & 1.62 & 0.60 & 0.437 \\
\hline Omnibus test & & & 9.24 & $<0.01$ \\
\hline \multicolumn{5}{|l|}{ Body fat percentage } \\
\hline Class 1 vs. class 2 & 6.96 & 1.38 & 25.29 & $<0.001$ \\
\hline Class 1 vs. class 3 & 5.26 & 1.26 & 17.30 & $<0.001$ \\
\hline Class 2 vs. class 3 & -1.70 & 1.21 & 1.99 & 0.158 \\
\hline Omnibus test & & & 27.48 & $<0.001$ \\
\hline \multicolumn{5}{|l|}{ Systolic blood pressure } \\
\hline Class 1 vs. class 2 & 3.49 & 3.28 & 1.13 & 0.287 \\
\hline Class 1 vs. class 3 & 5.04 & 2.76 & 3.34 & 0.0676 \\
\hline Class 2 vs. class 3 & 1.55 & 2.90 & 0.29 & 0.593 \\
\hline Omnibus test & & & 3.35 & 0.187 \\
\hline \multicolumn{5}{|l|}{ Diastolic blood pressure } \\
\hline Class 1 vs. class 2 & 0.63 & 2.16 & 0.08 & 0.768 \\
\hline Class 1 vs. class 3 & 1.43 & 1.75 & 0.67 & 0.411 \\
\hline Class 2 vs. class 3 & 0.80 & 2.11 & 0.14 & 0.703 \\
\hline Omnibus test & & & 0.68 & 0.712 \\
\hline \multicolumn{5}{|l|}{ TG } \\
\hline Class 1 vs. class 2 & -5.11 & 22.18 & 0.05 & 0.817 \\
\hline Class 1 vs. class 3 & -0.73 & 19.67 & 0.00 & 0.970 \\
\hline Class 2 vs. class 3 & 4.37 & 18.67 & 0.05 & 0.814 \\
\hline Omnibus test & & & 0.07 & 0.965 \\
\hline \multicolumn{5}{|l|}{ HDL cholesterol } \\
\hline Class 1 vs. class 2 & 1.09 & 2.23 & 0.23 & 0.626 \\
\hline Class 1 vs. class 3 & -1.88 & 2.17 & 0.75 & 0.384 \\
\hline Class 2 vs. class 3 & -2.97 & 2.14 & 1.92 & 0.165 \\
\hline Omnibus test & & & 1.98 & 0.370 \\
\hline \multicolumn{5}{|l|}{ FBS } \\
\hline Class 1 vs. class 2 & -2.37 & 6.66 & 0.13 & 0.721 \\
\hline Class 1 vs. class 3 & -1.25 & 6.06 & 0.04 & 0.836 \\
\hline Class 2 vs. class 3 & 1.12 & 4.83 & 0.05 & 0.816 \\
\hline Omnibus test & & & 0.13 & 0.936 \\
\hline \multicolumn{5}{|l|}{ GGT } \\
\hline Class 1 vs. class 2 & -19.4 & 7.29 & 7.06 & $<0.01$ \\
\hline Class 1 vs. class 3 & -7.14 & 6.38 & 1.25 & 0.262 \\
\hline Class 2 vs. class 3 & 12.25 & 8.70 & 1.98 & 0.158 \\
\hline
\end{tabular}


Table 4 Association between latent classes and cardiometabolic risk factors (Continued)

\begin{tabular}{lllll}
\hline Difference in means & Estimate & SE & Wald statistic & P-value \\
\hline Omnibus test & & & 7.44 & \\
Metabolic syndrome (difference in log means) & & & \\
Class 1 vs. class 2 & -0.76 & 0.46 & 2.67 & 0.102 \\
Class 1 vs. class 3 & 0.82 & 0.39 & 4.26 & 0.038 \\
Class 2 vs. class 3 & 0.05 & 0.43 & 0.01 & 0.902 \\
Omnibus test & & & 4.73 & 0.093
\end{tabular}

FBS fasting blood glucose, GGT gamma glutamyl transferase, HDL high-density lipoprotein, TG triglycerides

prevalence of metabolic syndrome (emotional eaters: $49 \%$, other eaters: $32 \%$ ), which means that emotional eating can be a risk factor for metabolic syndrome. Recently, another longitudinal study using the data of the Korean Healthy Twin study [29] showed that baseline emotional eating behaviour had strong association with concurrent, incident, and persistent metabolic syndrome, which was compatible with our study except that the previous study's results applied only to women. Emotional eating can be defined as eating in response to negative emotions or stress and is one of the many causes for weight gain or regaining weight after dieting [30]. It is known that stress and negative emotions can lead to a higher intake of palatable energy-dense foods, such as chocolate, cakes, biscuits, pizzas, hamburgers, French fries, and sausages [31]. Emotional eating might lead to increased intake of energy-dense foods and may induce weight gain, obesity, and metabolic syndrome. Patients with obesity already have a higher set point driven by hormonal balance and emotional eating in response to stress, which is governed by the reward system of the brain that can override the metabolic set point, leading to sustained weight gain above the metabolic set point [32]. In our study, the emotional eater group might have been driven by hedonic system over metabolic system of body weight regulation, which can lead to higher BMI and associated metabolic syndrome.

Despite their different dietary profiles, subjects in classes 1 and 2 showed no significant differences in cardiometabolic risk factors except for GGT. This might reflect similar distributions of age, sex, and underlying disease. Irregular unhealthy eaters were more likely to

Table 5 Odds ratio and 95\% confidence interval for metabolic syndrome in association with latent classes and covariates

\begin{tabular}{|c|c|c|c|}
\hline Variable & Odds ratio & 95\% confidence interval & $P$-value \\
\hline Class 1: healthy but unbalanced eaters & Ref & & \\
\hline Class 2: irregular, unhealthy eaters & 1.12 & $0.54,2.34$ & 0.761 \\
\hline Class 3: emotional eaters & 2.88 & $1.16,7.13$ & 0.012 \\
\hline Age $20-39$ years & Ref & & \\
\hline Age $40-59$ years & 1.04 & $0.31,3.54$ & 0.946 \\
\hline Age $>60$ years & 1.37 & $0.34,5.45$ & 0.657 \\
\hline Male & Ref & & \\
\hline Female & 0.94 & $0.35,2.55$ & 0.903 \\
\hline BMI $23-25 \mathrm{~kg} / \mathrm{m}^{2}$ & Ref & & \\
\hline $\mathrm{BMI}>25 \mathrm{~kg} / \mathrm{m}^{2}$ & 2.62 & $1.00,6.89$ & 0.051 \\
\hline Liver enzymes < 40 mg/dL & Ref & & \\
\hline Liver enzymes 40-120 mg/dL & 1.81 & $0.89,3.73$ & 0.108 \\
\hline Liver enzymes > $120 \mathrm{mg} / \mathrm{dL}$ & 5.21 & $1.47,18.52$ & 0.010 \\
\hline Non-smoker & Ref & & \\
\hline Ex-smoker & 0.94 & $0.33,2.64$ & 0.901 \\
\hline Current smoker & 3.03 & $1.04,8.83$ & 0.042 \\
\hline No drinking & Ref & & \\
\hline Drinking & 0.58 & $0.25,1.32$ & 0.193 \\
\hline Regular exercise & Ref & & \\
\hline No exercise & 1.35 & $0.65,2.79$ & 0.415 \\
\hline
\end{tabular}


have irregular meals, dine out, and consume alcohol (which might explain the increased GGT in this group). In contrast, classes 2 and 3 had similar dietary behaviour patterns, except for emotional eating, which might have contributed to their higher rates of binge eating, irregular meals, and frequent snacking, which in turn could lead a higher BMI and a higher likelihood of metabolic syndrome.

In a study performed in the Netherlands, emotional eating was found to be a mediator between depression and 5-year weight gain in mothers [33]. In that study, depressive symptoms were associated with higher rates of emotional eating, which resulted in an increase in BMI independent of depressive symptoms. Emotional eating is also closely associated with insufficient sleep and poor sleep quality [30]. Insufficient sleep can cause more negative emotions and interferes with regulation of emotion through neurobiological, cognitive, and behavioural pathways. Therefore, identifying the subtype of obesity, such as emotional eating, can facilitate tailored treatment, such as training in emotional regulation skills or improving other lifestyle factors such as sleep.

The cross-sectional nature of this study meant that we could not detect a difference in the baseline cardiometabolic risk factors between subjects with healthy dietary behaviours and those with unhealthy behaviours (classes 1 and 2). However, it was worthwhile to subtype the group with irregular unhealthy dietary behaviour for the purposes of prediction and intervention. Several studies have suggested that an unhealthy dietary pattern can lead to increased weight, BMI, and waist circumference $[34,35]$ and that this group of patients might achieve greater weight loss if they receive more tailored interventions targeting multiple health behaviours rather than strategies that target a single behaviour [36].

To our knowledge, this is the first study in Korea that has used LCA to classify dietary behaviour and explore its association with metabolic syndrome in overweight or obese adults. Dietary behaviours are highly interrelated, often concurrent, and affected by a complex interplay of multiple risk factors, including socioeconomic status and other health-related behaviours. LCA can address the complexity of dietary behaviour and capture meaningful key patterns [27].

Logistic regression analysis of metabolic syndrome and LCA-derived emotional eating showed significant associations but not when irregular unhealthy eaters were compared with healthy but unbalanced eaters, indicating that some components of dietary behaviour have a greater effect than others.

The findings of this study suggest a practical approach for identifying different phenotypes amongst individuals who are overweight or obese. Emotional eaters should be prioritised for emotional regulation and encouragement of emotional well-being. A recent review suggested that mindfulness and meditation have the potential to decrease emotional eating [37].

According to the American Heart Association, the timing and frequency of meals is also important in the management of cardiometabolic risk factors [38]. Regular meals with avoidance of late-night snacking can attenuate the risk of heart disease and diabetes mellitus. In this regard, identifying individuals with unhealthy dietary behaviours, such as irregular mealtimes or frequent snacking (class 2), and managing them with the focus on eating patterns might help achieve a healthy cardiometabolic profile as well as effective weight reduction.

This study has several limitations. First, it was not possible to use a validated dietary questionnaire because the study was based on a retrospective review of medical charts. Second, categorising the components of the dietary behaviour questionnaire into nine items could be considered subjective; however, we attempted to offset this problem by referencing a dietary pattern evaluation tool devised for Koreans [23]. Third, the questionnaire used in the study was self-administered, which might have introduced a degree of reporting bias. Fourth, the study data were obtained from a single hospital weight management clinic and might not be generalisable to other populations. Dietary behaviours can be influenced by sex, age, and socioeconomic factors [39, 40]. Neither sex-specific nor age-specific LCA could be performed in this study because of the relatively small number of patients enrolled after exclusion of those with missing data. Lastly, since depression seemed strongly associated with emotional eaters, evaluating depressive symptoms were important tools in understanding emotional eaters compared with other types of eaters. However, no validated questionnaires were available regarding depression, we used operational definition of depression using the ICD10 codes and prescription [18]. Although it has a high specificity (94.3\%), its moderate sensitivity (61.4\%) might limit the exact status of depression amongst the study subjects. Further detailed methods for detecting depression or sleep problem will be required using validated questionnaires relevant to eating disorder or eating behaviours.

Despite its drawbacks, this study shows that subtyping obesity-related dietary behaviours could be a guide to prioritising the components that should be put in place for tailored cognitive behavioural therapy. Further rigorous research is needed for these interventions to be effective in weight management.

\section{Conclusions}

In conclusion, we have shown that LCA-driven obesity phenotyping can be a useful tool for assessment and management of obesity as well as metabolic syndrome. 
In this study, emotional eaters had higher BMI and were more likely to have metabolic syndrome than other types of eaters. Emotional eaters might benefit from strategies targeting emotional regulation. People with irregular unhealthy dietary behaviours, such as irregular mealtimes or frequent night snacking, could be candidates for cognitive behavioural therapy focusing on healthy eating behaviours, which can also contribute to a favourable cardiometabolic profile.

\section{Abbreviations}

ALT: Alanine transaminase; AST: Aspartate transaminase; BMI: Body Mass Index; eGFR: Estimated glomerular filtration rate; FBS: Fasting blood glucose; GGT: Gamma glutamyl transferase; HbA 1 c: Glycated haemoglobin; HDL: Highdensity lipoprotein; LDL: Low-density lipoprotein; LCA: Latent class analysis; TG: Triglycerides

\section{Acknowledgements}

Not applicable.

\section{Authors' contributions}

JHP and JYK conceived the research question. JYK developed the theory and performed the analysis. SHK, YMP, and HSY collected, cleansed, and analysed the nutritional data. JHK and JYK critically interpreted the data. JHP took the lead in writing the manuscript. All authors discussed the results and contributed to the final manuscript. The author(s) read and approved the final manuscript.

\section{Funding}

This work was supported by grant no. 12-2013-005 from the SNUBH Research Fund.

\section{Availability of data and materials}

The datasets used and analysed during the current study are available from the corresponding author on reasonable request.

\section{Ethics approval and consent to participate}

The study protocol was approved in advance of enrolling patients by the Institutional Review Board at Seoul National University Bundang Hospital (IRB no. B-1904-532-114). The need for informed consent was waived in view of the retrospective nature of the study and the anonymity of the data.

\section{Consent for publication}

Not applicable.

\section{Competing interests}

No benefits in any form have been received or will be received from a commercial party related directly or indirectly to the subject of this article.

\section{Author details}

${ }^{1}$ Department of Family Medicine, Jeju National University Hospital, Jeju, South Korea. ${ }^{2}$ Department of Family Medicine, Seoul National University Bundang Hospital and Seoul National University College of Medicine, 82, Gumi-ro 173 Beon-gil, Bundang-gu, Seongnam, Gyeonggi-do 13620, Republic of Korea. ${ }^{3}$ Nutrition Care Services, Seoul National University Bundang Hospital, Seongnam, South Korea. ${ }^{4}$ Department of Psychiatry, Seoul National University Bundang Hospital, Seongnam, South Korea.

\section{Received: 8 July 2020 Accepted: 12 October 2020}

Published online: 16 October 2020

\section{References}

1. World Health Organization: Obesity and overweight. https://www.who.int/ en/news-room/fact-sheets/detail/obesity-and-overweight (2018).

2. Korean Centers for Disease Control and Prevention. Korean national health \& nutrition examination survey 2017. Available from: http://www.cdc.go.kr/ board.es?mid=a20602010000\&bid=0034\&act=view\&list_no=140978.

3. Cetin D, Lessig BA, Nasr E. Comprehensive evaluation for obesity: beyond body mass index. J Am Osteopath Assoc. 2016;116:376-82.
4. Kahn HS, Bullard KM. Beyond body mass index: advantages of abdominal measurements for recognizing cardiometabolic disorders. Am J Med. 2016; 129:74-81 e2.

5. Monteiro CA, Moubarac JC, Cannon G, Ng SW, Popkin B. Ultra-processed products are becoming dominant in the global food system. Obes Rev. 2013;14(Suppl 2):21-8.

6. Mendenhall E, Singer M. The global syndemic of obesity, undernutrition, and climate change. Lancet. 2019;393:741.

7. Bellisle F. Meals and snacking, diet quality and energy balance. Physiol Behav. 2014;134:38-43.

8. Mohammadbeigi A, Asgarian A, Moshir E, Heidari H, Afrashteh S, Khazaei S, et al. Fast food consumption and overweight/obesity prevalence in students and its association with general and abdominal obesity. J Prev Med Hyg. 2018;59:E236-E40.

9. Sominsky L, Spencer SJ. Eating behavior and stress: a pathway to obesity. Front Psychol. 2014:5:434.

10. Ferriday D, Brunstrom JM. 'I just can't help myself': effects of food-cue exposure in overweight and lean individuals. Int J Obes. 2011;35:142-9.

11. Tumin R, Anderson SE. Television, home-cooked meals, and family meal frequency: associations with adult obesity. J Acad Nutr Diet. 2017;117:937-45.

12. Marijn Stok F, Renner B, Allan J, Boeing H, Ensenauer R, Issanchou S, et al. Dietary behavior: an interdisciplinary conceptual analysis and taxonomy. Front Psychol. 2018;9:1689.

13. Field AE, Camargo CA Jr, Ogino S. The merits of subtyping obesity: one size does not fit all. JAMA. 2013;310:2147-8.

14. Mathur C, Stigler M, Lust K, Laska M. A latent class analysis of weight-related health behaviors among 2- and 4-year college students and associated risk of obesity. Health Educ Behav. 2014;41:663-72.

15. Huh J, Riggs NR, Spruijt-Metz D, Chou CP, Huang Z, Pentz M. Identifying patterns of eating and physical activity in children: a latent class analysis of obesity risk. Obesity (Silver Spring). 2011;19:652-8.

16. Gholami A, Sohrabi M, Abbasi-Ghahramanloo A, Moradpour F, Safiri S, Maadi $M$, et al. Identifying the pattern of unhealthy dietary habits among an Iranian population: a latent class analysis. Med J Islam Repub Iran. 2018;32:69.

17. Lanza ST, Rhoades BL. Latent class analysis: an alternative perspective on subgroup analysis in prevention and treatment. Prev Sci. 2013;14:157-68.

18. Doktorchik C, Patten S, Eastwood C, Peng M, Chen G, Beck CA, et al. Validation of a case definition for depression in administrative data against primary chart data as a reference standard. BMC Psychiatry. 2019;19(1):9.

19. National Cholesterol Education Program (NCEP) Expert Panel on Detection, Evaluation, and Treatment of High Blood Cholesterol in Adults (Adult Treatment Panel III). Third report of the National Cholesterol Education Program (NCEP) expert panel on detection, evaluation, and treatment of high blood cholesterol in adults (adult treatment panel III) final report. Circulation. 2002;106:3143-421.

20. Jo JS, Kim KN. Development of a questionnaire for dietary habit survey of Korean adults. Korean J Community Nutr. 2014;19:258-73.

21. Saneei P, Esmaillzadeh A, Keshteli AH, Feizi A, Feinle-Bisset C, Adibi P. Patterns of dietary habits in relation to obesity in Iranian adults. Eur J Nutr. 2016;55:713-28.

22. Barrington WE, Beresford SAA, et al. Nutrients. 2019;11:E2320.

23. Lee YD, Kim KW, Choi KS, Kim M, Cho YJ, Sohn C. Development of dietary pattern evaluation tool for adults and correlation with dietary quality index. Nutr Res Pract. 2016;10:305-12.

24. Lee J-S, Kim H-Y, Hwang J-Y, Kwon S, Chung HR, Kwak T-K, et al. Development of nutrition quotient for Korean adults: item selection and validation of factor structure. J Nutr Health. 2018:51:340-56.

25. Lanza ST, Collins LM, Lemmon DR, Schafer JL. PROC LCA: A SAS procedure for latent class analysis. Struct Equ Model. 2007;14:671-94.

26. PROC LCA \& PROC LTA (Version 1.3.2) [Software] [Internet]. University Park: The Methodology Center, Penn State 2015. Available from: http:// methodology.psu.edu.

27. PROC LCA \& PROC LTA users' guide (Version 1.3.2). [Internet]. University Park: The Methodology Center, Penn State. 2015. Available from: http:// methodology.psu.edu.

28. Kongsted A, Nielsen AM. Latent class analysis in health research. J Physiother. 2017:63:55-8.

29. Lanza ST, Tan X, Bray BC. Latent class analysis with distal outcomes: a flexible model-based approach. Struct Equ Model. 2013;20:1-26.

30. Song YM, Lee K. Eating behavior and metabolic syndrome over time. Eat Weight Disord. 2020;25(3):545-52. 
31. Konttinen $\mathrm{H}$. Emotional eating and obesity in adults: the role of depression, sleep and genes. Proc Nutr Soc. 2020:1-7. online ahead of print.

32. Konttinen H, Männistö S, Sarlio-Lähteenkorva S, Silventoinen K, Haukkala A. Emotional eating, depressive symptoms and self-reported food consumption. A population-based study. Appetite. 2010;54:473-9.

33. Yu YH, Vasselli JR, Zhang Y, Mechanick Jl, Korner J, Peterli R. Metabolic vs. hedonic obesity: a conceptual distinction and its clinical implications. Obes Rev. 2015;16(3):234-47.

34. van Strien T, Winkens L, Toft MB, Pedersen S, Brouwer I, Visser M, et al. The mediation effect of emotional eating between depression and body mass index in the two European countries Denmark and Spain. Appetite. 2016; 105:500-8.

35. de Castro MB, Sichieri R, Barbosa Brito Fdos S, Nascimento S, Kac G. Mixed dietary pattern is associated with a slower decline of body weight change during postpartum in a cohort of Brazilian women. Nutr Hosp. 2014;29:51925.

36. Xu X, Byles J, Shi Z, McElduff P, Hall J. Dietary pattern transitions, and the associations with BMI, waist circumference, weight and hypertension in a 7year follow-up among the older Chinese population: a longitudinal study. BMC Public Health. 2016;16:743.

37. Sweet SN, Fortier MS. Improving physical activity and dietary behaviours with single or multiple health behaviour interventions? A synthesis of metaanalyses and reviews. Int J Environ Res Public Health. 2010;7:1720-43.

38. Katterman SN, Kleinman BM, Hood MM, Nackers LM, Corsica JA. Mindfulness meditation as an intervention for binge eating, emotional eating, and weight loss: a systematic review. Eat Behav. 2014;15:197-204.

39. St-Onge MP, Ard J, Baskin ML, Chiuve SE, Johnson HM, Kris-Etherton P, et al. Meal timing and frequency: implications for cardiovascular disease prevention: a scientific statement from the American Heart Association. Circulation. 2017;135:e96-e121.

40. Beydoun MA. The interplay of gender, mood, and stress hormones in the association between emotional eating and dietary behavior. J Nutr. 2014; 144:1139-41.

\section{Publisher's Note}

Springer Nature remains neutral with regard to jurisdictional claims in published maps and institutional affiliations.

Ready to submit your research? Choose BMC and benefit from:

- fast, convenient online submission

- thorough peer review by experienced researchers in your field

- rapid publication on acceptance

- support for research data, including large and complex data types

- gold Open Access which fosters wider collaboration and increased citations

- maximum visibility for your research: over $100 \mathrm{M}$ website views per year

At $\mathrm{BMC}$, research is always in progress.

Learn more biomedcentral.com/submissions 